3. Lindsay M.P., Norrving B., Sacco R.L., et al. (2019). World Stroke Organization (WSO): Global Stroke Fact Sheet 2019. Int J Stroke, 14(8), 806-817.

4. Feigin V.L., Krishnamurthi R.V., Parmar $P_{\text {., }}$ et al. (2015). Update on the Global Burden of Ischemic and Hemorrhagic Stroke in 1990-2013: The GBD 2013 Study. NED, 45(3), 161-176.

5. O'Donnell M.J., Chin S.L., Rangarajan S., et al. (2016). Global and regional effects of potentially modifiable risk factors associated with acute stroke in 32 countries (INTERSTROKE): a case-control study. Lancet, 388(10046), 761-775.

6. Kissela B.M., Khoury J.C., Alwell K., et al. (2012). Age at stroke: Temporal trends in stroke incidence in a large, biracial population. Neurology, 79(17), 1781-1787.
7. Phạm Phước Sung (2019), Kết quả điều trị nhồi máu não trong giai đoan tứ 3 đến 4,5 giờ bằng thuốc tiêu huyết khối Ailteplase liều thấp, Luận án tiến sĩ Trường Đại học Y Hà Nội.

8. Nguyễn Quang Ân, Nguyễn Minh Hiên, Nguyễn Hoàng Ngọc, et al. (2018). Nghiên cứu mối liên quan giữa đắc điểm lâm sang và hình ảnh cắt lớp vi tính ở bệnh nhân Đột quy nhồi máu não cấp trong 6 giờ đầu kể từ khi khởi phát. Tap chí Y Dước hoc quân sự, 4, 84-92.

9. Đoàn Vũ̃ Xuân Lộc, Nguyễn Thanh Thảo, Hoàng Minh Lợi, et al. (2014). Ứng dụng thang điểm ASPECTS trong tiên lượng sớm dự hậu đột quy nhồi máu não cấp. Tap chí $Y$ Dược hoc Trường Đại học Y Dược Huế, 22 + 23, 169 (9).

\title{
YẾU TỐ TIÊN LƯỢNG THÀNH CÔNG CUẢ PHƯƠNG THỨC AVAPS Ở BÊ̂NH NHÂN ĐợT CẤP BỆNH PHỔI TẮC NGHẼN MẠN TÍNH (COPD) ĐƯợC THÔNG KHÍ NHÂN TẠO KHÔNG XÂM NHÂ̂P
}

\section{TÓM TẮT.}

Mục tiêu: Đánh giá yếu tố tiên lượng thành công của bểnh nhân đợt cấp bệnh phổi tắc nghẽn mạn tính (COPD) được thổng khí nhân tạo không xâm nhập bằng phương thức AVAPS. Phương pháp: Nghiển cứu tiến cứu so sánh trước sau can thiệp trên 40 bệnh nhân đợt cấp COPD nhập khoa Cấp cứu bệnh viện Bạch Mai có chỉ định thông khí không xâm nhập từ tháng 05/2019 đến tháng 8/2020. Các thông số theo dõi chính như tuổi, giới, các chỉ số khí máu: $\mathrm{pH}$, $\mathrm{PaCO}_{2}, \mathrm{PaO}_{2}, \mathrm{HCO}_{3}, \mathrm{PaO}_{2} / \mathrm{FiO}_{2}$, các thông số thở máy: Vt, Vte, PIP, Leak được thu thập tại các thời điểm: trước thở AVAPS, sau thở AVAPS 3 giờ, sau 6 giờ, sau 12 giờ. Bệnh nhân được đánh giá thành công khi không phải đặt nội khí quản, lâm sàng và khí máu ổn định sau bỏ máy 24 giờ. Kết quả: Nghiên cứu trên 40 bệnh nhân (tuổi trung bình 70,3 $\pm 9,87$ tuổi; 7,5\% nữ giới) cho kết quả có $29(72,5 \%)$ bệnh nhân thở máy thành công. Ở nhóm thành công, PaCO2, HCO3, PIP, Leak giảm dân theo thời điểm theo dõi, giảm nhanh nhất từ T0 đến T3-6; Vt, Vte tăng dần $(p<0,05)$; Ở nhóm thất bai PaCO2, PaO2, PIP, Vt, Vte tăng dấn theo thời điểm. $\mathrm{PaCO}_{2}$ với điểm cắt $\geq 88 \mathrm{mmHg}$ (diên tích dưới đường cong ROC, AUC $=0,8364$ ), PIP với điểm cắt $\geq 17 \mathrm{cmH}_{2} \mathrm{O}$ (AUC=0,8871), Leak với điểm cắt $\geq 29$ lít/phút (AUC $=0,7884)$, cho độ nhạy, độ đặc hiệu, giá trị dự báodương tính và giá trị dự báo ẩm tính cao. Kết luận: Các thông số như PaCO2, PIP và leak tại thời điểm bắt

\footnotetext{
${ }^{1}$ Trung tâm Cấp cứu A9- Bênh viên Bach Mai,

${ }^{2}$ Trung tâm Chống độc - Bệnh viện Bạch Mai

${ }^{3}$ Bệnh viện Đa khoa Nông Ñghiệp
}

Chịu trách nhiệm chính: Đố Ngọc Sơn

Email: sonngocdo@gmail.com

Ngày nhận bài: 9.3.2021

Ngày phản biên khoa học: 28.4.2021

Ngày duyệt bài: 7.5.2021

\section{Đỗ Ngọc Sơn ${ }^{1}$, Đặng Thị Xuân ${ }^{2}$, Vũ Trung Kiên ${ }^{3}$}

đâu tiến hành thở AVAPS là những yếu tố tiên lượng thành công khi thông khí nhân tạo không xâm nhập cho bệnh nhân đợt cấp COPD.

Ti̛ khóa: Thông khí nhân tao không xâm nhập, AVAPS, đợt cấp bệnh phổi tắc nghẽn mạn tính

\section{SUMMARY}

\section{SUCCESSFUL PREDICTION FACTORS OF AVAPS IN PATIENTS WITH THE ACUTE EXACERBATION OF CHRONIC PULMONARY OBSTRUCTIVE DISEASE (COPD) ON NON- INVASIVE MECHANICAL VENTILATION}

Objective: to identify a successful prediction factors in patients with exacerbation of chronic obstructive pulmonary disease (COPD) who were on noninvasive mechanical ventilation by Average Volume Assured Pressure Support (AVAPS) mode. Methods: A prospective, pre \& post-intervention comparison study on 40 non-invasive ventilated patients with COPD exacerbations admitted to the Emergency Department of Bach Mai Hospital from May 2019 to August 2020. The main variables such as age, sex, blood gas indices: $\mathrm{pH}, \mathrm{PaCO} 2, \mathrm{PaO} 2, \mathrm{HCO}$, $\mathrm{PaO} 2 / \mathrm{FiO} 2$ ratio, mechanical ventilation parameters: Vt, Vte, PIP, Leak were collected at the timelines: before AVAPS, 3 hours, 6 hours, 12 hours after AVAPS. Successful ventilation was defined as no requirement for endotracheal intubation, clinical and blood gas stability within 24 hours. Results: The study on 40 patients (mean age $70.3 \pm 9.87$ years; $7.5 \%$ women) showed that there were $29(72.5 \%)$ patients with successful ventilation. In the successful group, $\mathrm{PaCO} 2, \mathrm{HCO} 3, \mathrm{PIP}$, Leak levels decreased gradually, the fastest decrease was occurred from T0 to T3-6; Vt, Vte levels increased gradually ( $p<0.05)$; In the failed group PaCO2, PaO2, PIP, Vt, Vte levels increased gradually, leak level decreased gradually ( $p$ 
$<0.05$ ). PaCO2 with cut-off $\geq 88 \mathrm{mmHg}$ (area under ROC curve, AUC $=0.8364$ ), PIP with cut-off $\geq 17$ $\mathrm{cmH} 2 \mathrm{O}$ (AUC $=0.8871$ ), Leak with cut-off $\geq 29$ liters $/ \min (A U C=0.7884$ ) provided high sensitivity, specificity, positive predictive value and negative predictive value. Conclusion: The successful prediction factors for AVAPS were PaCO2, PIP and leak at the initiation of the non-invasive ventilation for patients with the acute exacerbation of COPD.

Keyword: Noninvasive mechanical ventilation, AVAPS, ACOPD

\section{I. ĐĂT VẤN ĐỀ}

Bệnh phổi tắc nghẽn mạn tính (COPD) là nguyên nhân gây tử vong ngày càng phổ biến. Hiện là nguyên nhân tử vong hàng thứ 4 thế giới và dự kiến là thứ 3 vào năm 2020 [1]. Bệnh nhân COPD chiếm khoảng trên $25 \%$ bệnh nhân tại khoa hồi sức cấp cứu [2]. Tiên lượng ở đối tượng này là đặc biệt khó khi có đặt ônng nội khí quản và thở máy xâm nhập do có liên quan đến kéo dài thời gian nằm điều trị tại khoa hồi sức cấp cứu, tăng tỷ lệ tử vong khi nhập viện và sau xuất viện. Tỷ lệ tử vong khi nhập viện khoảng $8 \%-25 \%$ [3] và tỷ lệ tử vong trong vòng 1 năm sau xuất viện từ các khoa chăm sóc đặt biệt từ 35\% đến 48\% [4]. Phương thức thông khí nhân tạo không xâm nhập (TKNTKXN) được sử dụng trong điêu trị cho bệnh nhân COPDvì một số căn nguyên khác nhau. Thông khí nhân tạo hai mức áp lực dương theo thời gian (BiPAP S/T) từ lâu đã được sử dụng trên các bệnh nhân đợt cấp COPD và đã chứng minh được hiệu quả. Tuy nhiên phương thức này vẫn còn những hạn chế khi bệnh nhân thay đổi tư thế nhiều, thường gặp trên bệnh nhân trong giai đoạn cấp. Thông khí hỗ trợ áp lực đảm bảo thể tích (AVAPS) cho phép thiết lập dung tích thở $(\mathrm{Vt})$ cố định và đầu ra của hệ thống tự động điều chinh dựa trên sự thay đổi của áp lực thở ra. Những lợi íchlâu dài của nó đã được chứng minh ở những bệnh nhân bị COPD [5], [6]. Liệu AVAPS có hiệu quả cho những bệnh nhân COPD giai đoạn cấp hay không?. Tiên lượng hiệu quả của phương pháp này phụ thuộc vào chỉ số nào? Vì vậy, chúng tôi chúng tôi tiến hành nghiên cứu này nhẳm mục tiêu xác định các yếu tố tiên lượng thành công của phương thức AVAPS ở bệnh nhân đợt cẫp COPD được thông khí nhân tạo không xâm nhập.

\section{II. ĐỐI TƯỢNG VÀ PHƯƠNG PHÁP NGHIÊN CứU \\ 2.1. Đối tượng nghiên cứu \\ - Tiêu chuẩn lứa chon:}

o Bệnh nhân được chẩn đoán đợt cấp COPD theo GOLD 2019 nhập khoa Cấp cứu có chỉ định thông khí không xâm nhập
○ Có suy hô hấp cấp tính: Khó thở nặng lên, $\mathrm{pH}<7.35, \mathrm{PaCO} 2>45$, tần số thở > 25 lần/ phút, $\mathrm{PaO} 2<60 \%$.

- Tiêu chuẩn loại trừ: Ngừng thở, huyết động không ổn định, có rối loạn tri giác, tăng tiết dịch, mới phẫu thuật vùng đầu mặt và đường tiêu hóa, chấn thương vùng đầu mặt và đường tiêu hóa trên, mất phản xạ ho và nuốt,tắc nghẽn đường hô hấp trên, nôn hoặc có nguy cơ nôn, chấn thương ngực kín có tràn khí màng phổi chưa được dẫn lưu, suy tim giai đoạn mất bù, rối loạn đông cầm máu nặng, bênh lí thần kinh cơ mức độ nặng. Bệnh nhân không hợp tác hoặc người nhà không đồng ý hợp tác tham gia nghiên cứu.

2.2. Thời gian địa điểm nghiên cứu:

Thời gian nghiên cứu:Từ tháng 05/2019 đến tháng 8/2020

- Địa điểm nghiên cứu: Khoa Cấp Cứu, Bệnh viên Bach Mai.

2.3. Thiết kế nghiên cứu: Nghiên cứu tiến cứu can thiệp.

2.4. Cỡ mẫu nghiên cứu: Tất cả các bệnh nhân nhập khoa Cấp cứu có chỉ định thông khí không xâm nhập. Tổng cộng 40 bệnh nhân.

\subsection{Quá trình thu thập số liệu}

2.5.1. Tiêu chuẩn đánh giá kết quả điều trị:

- Thành công: không phải đặt nội khí quản, lâm sàng và khí máu ổn định sau bỏ máy 24 giờ.

- Thất bại: phải đặt NKQ để TKNTXN, thất bại muộn khi suy hô hấp tái phát sau bỏ máy 24h, phải can thiệp bằng thở máy xâm nhập.

\subsubsection{Các bước tiến hành nghiên cứu}

- Đối tượng nghiên cứu vào viện được hỏi tiền sử, bệnh sử, khám lâm sàng để hướng đến chẩn đoán đợt cấp COPD và các dấu hiệu suy hô hấp.

- Các thông số về cận lâm sàng: Công thức máu, máu lắng, CRP, sinh hóa máu cơ bản, khí máu động mạch, chụp phim phổi.

- Các thông số theo dõi chính bao gồm: Mạch, huyết áp, nhịp thở, $\mathrm{SpO}_{2}$, khí máu $(\mathrm{pH}$ $\mathrm{PaO}_{2}, \mathrm{PaCO}_{2}, \mathrm{HCO}^{-}$) được thu thập tại các thời điểm: Trước thở AVAPS, sau thở AVAPS 3 giờ, sau 6 giờ, sau 12 giờ, kết thúc.

- Cài đặt thông số máy ban đầu với áp lực (IPAPmin) mức $8 \mathrm{cmH} 20$, mức (IPAPmax) mức $20 \mathrm{cmH} 20$ áp lực thì thở ra (EPAP) mức từ 4$5 \mathrm{cmH} 2 \mathrm{O}$, tần số thở $\mathrm{f}=15$ lần/phút, $\mathrm{FiO} 2$ : đảm bảo $\mathrm{SpO} 2>90 \%$. Chọn Mask mũi miệng, chụp thử Mask 10 phút và cài đặt mức áp lực, chỉnh oxy đến lúc phù hợp bệnh nhân cảm thấy dễ thở và $\mathrm{SpO} 2$ khoảng $90 \%$, lắp Mask cố định cho bệnh nhân.

2.6. Phân tích số liệu: Làm sạch và mã hóa 
dữ liệu thu thập được, nhập số liệu vào phần mềm SPSS 16.0.

Tất cả dữ liệu được biểu thị dưới dạng trung bình \pm độ lệch chuẩn (SD) cho các biến liên tục và dưới dạng tỷ lệ phần trăm cho các biến phấn loại. Các biến liên tục có phân phối chuẩn được kiểm tra bằng phép thử Kolmogorov-Smirnov và được so sánh bằng phép thử T-Test. Chúng tôi đã sử dụng phân tích phương sai lặp lại (repeated ANOVA) để so sánh khả năng của các biến khác nhau $\left(\mathrm{pH}, \mathrm{pCO} 2, \mathrm{HCO}\right.$, $\mathrm{PaO} 2 / \mathrm{FiO}^{2}$, Vt, Ve, PIP, Leak) để dự đoán kết quả điều trị ở bệnh nhân thành công và đối chứng. Giá trị $P$ $<0,05$ được coi là có ý nghĩa thống kê.

\section{KẾT QUẢ NGHIÊN CỨU}

Bảng 2: Đặc điểm chung đôî tượng nghiên cứu ( $n=40)$

\begin{tabular}{|c|c|c|c|}
\hline \multicolumn{2}{|c|}{ Đặc điếm } & $\mathbf{N}$ & $\mathbf{\%}$ \\
\hline \multirow{4}{*}{$\begin{array}{c}\text { Nhóm } \\
\text { tuổi }\end{array}$} & $<60$ & 6 & 15 \\
\cline { 2 - 4 } & $60-80$ & 27 & 67,5 \\
\cline { 2 - 4 } & $\geq 80$ & 7 & 17,5 \\
\cline { 2 - 4 } & Trung bình ( \pm SD) & $70,3 \pm 9,87$ \\
\hline
\end{tabular}

\begin{tabular}{c|c|c|c|}
\multirow{2}{*}{ Giới } & Nam & 37 & 92,5 \\
\cline { 2 - 4 } & Nữ & 3 & 7,5 \\
\hline
\end{tabular}

Nhận xét: Trong nghiên cứu độ tuối trung bình là 70,3 \pm 9,87 tuổi; đa số đối tượng nằm trong độ tuổi $60-80$. Nam giới chiếm phần lớn bệnh nhân (92,5\%).

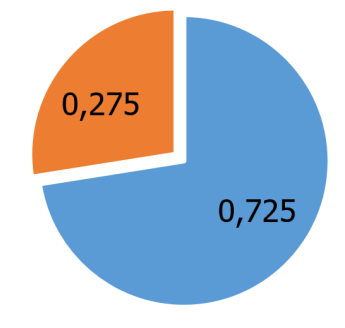

" Thành công " Thất bại

\section{Biểu đồ 2: Kêt quả điều trị thành công và thât bai thở AVAPS $(n=40)$}

Nhận xét: Kết quả thở AVAPS cho thấy có $29(72,5 \%)$ bệnh nhân thành công, không phải đặt nội khí quản, lâm sàng và khí máu ổn định sau bỏ máy 24 giờ.

\begin{tabular}{|c|c|c|c|c|c|}
\hline & Nhóm & $\mathbf{T O}(\bar{x} \pm S D)$ & $\mathbf{T 1}\left({ }^{\bar{X}} \pm \mathrm{SD}\right)$ & T2( $(\bar{X} \pm S D)$ & $\mathbf{p}$ \\
\hline \multirow{2}{*}{$\mathrm{pH}$} & Thành công & $7,30 \pm 0,04$ & $7,30 \pm 0,04$ & $7,30 \pm 0,04$ & 0,36 \\
\hline & Thất bại & $7,20 \pm 0,03$ & $7,20 \pm 0,04$ & $7,20 \pm 0,06$ & 0,283 \\
\hline \multirow{2}{*}{$\begin{array}{c}\mathrm{PaCO} 2 \\
(\mathrm{mmHg})\end{array}$} & Thành cồng & $75,77 \pm 11,84$ & $65,52 \pm 8,75$ & $60,32 \pm 9,53$ & $<0,001$ \\
\hline & Thất bại & $89,34 \pm 6,27$ & $93,77 \pm 7,72$ & $98,89 \pm 11,45$ & 0,0032 \\
\hline \multirow{2}{*}{$\begin{array}{c}\mathrm{PaO2} \\
(\mathrm{mmHg})\end{array}$} & Thành cồng & $78,25 \pm 18,85$ & $96,44 \pm 9,63$ & $96,43 \pm 5,61$ & $<0,001$ \\
\hline & Thất bai & $72,00 \pm 7,32$ & $85,76 \pm 6,37$ & $81,82 \pm 11,16$ & $<0,001$ \\
\hline \multirow{2}{*}{$\begin{array}{c}\mathrm{HCO3} \\
(\mathrm{mmHg})\end{array}$} & Thành cồng & $\pm 4,26$ & $37,95 \pm 3,46$ & $37,17 \pm 3,63$ & $<0,001$ \\
\hline & Thất bai & $44,6 \pm 3,28$ & $45,23 \pm 3,95$ & $45,75 \pm 4,62$ & 0,439 \\
\hline \multirow{2}{*}{$\mathrm{PaO} 2 / \mathrm{FiO}_{2}$} & Thành cồng & $234,82 \pm 54,90$ & $278,89 \pm 38,61$ & $375,87 \pm 451,04$ & 0,118 \\
\hline & & 63,32 & $226,54 \pm 45,81$ & $224,81 \pm 49,44$ & 0,906 \\
\hline \multirow{2}{*}{$\mathrm{Vt}(\mathrm{ml})$} & Thành cồng & $343,96 \pm 65,48$ & $485,51 \pm 26,12$ & $481,20 \pm 22,10$ & $<0,001$ \\
\hline & Thất bại & $324,54 \pm 11,28$ & $403,63 \pm 50,05$ & $411,81 \pm 39,45$ & $<0,001$ \\
\hline \multirow{2}{*}{$\begin{array}{c}\tilde{V} e \\
\text { (lít/phút) }\end{array}$} & Thàn & $9,36 \pm 0,60$ & $11,54 \pm 0,85$ & $10,60 \pm 0,90$ & $<0,001$ \\
\hline & & 0,43 & $12,18 \pm 1,53$ & $12,63 \pm 1,50$ & $<0,001$ \\
\hline \multirow{2}{*}{$\begin{array}{c}\mathrm{PIP} \\
\left(\mathrm{cmH}_{2} \mathrm{O}\right)\end{array}$} & Thành cồng & $15,06 \pm 0,92$ & $14,68 \pm 0,92$ & $14,44 \pm 1,12$ & $<0,001$ \\
\hline & Thất bai & $16,63 \pm 0,80$ & $17,18 \pm 0,75$ & $17,72 \pm 0,64$ & $<0,001$ \\
\hline \multirow{2}{*}{$\begin{array}{c}\text { Leak } \\
\text { (lít/phút) }\end{array}$} & Thành cống & $26,79 \pm 2,00$ & $16,62 \pm 1,78$ & $16,62 \pm 1,32$ & $<0,001$ \\
\hline & Thất bại & $28,63 \pm 1,28$ & $18,72 \pm 0,78$ & $23,45 \pm 1,36$ & $<0,001$ \\
\hline
\end{tabular}

Nhận xét: Cả 2 nhóm thành công và thất bai chỉ số khí máu: $\mathrm{PaO} 2, \mathrm{PaO} 2 / \mathrm{FiO}_{2}$ tăng , $\mathrm{PaCO}$, HCO3 nhóm thành công giảm có ý nghĩa thống kể $(p<0,001)$. Các thông số Vt, Ve tăng cả 2 nhóm, PIP, Leak giảm nhóm thành công qua các thởi điểm $(p<0,001)$.

Bảng 3. Giá trị dư báo của PIP và Leak trong kết quả can thiệp $(n=40)$

\begin{tabular}{|c|c|c|c|c|c|c|}
\hline Chỉ số & AUC & Điểm cắt & $\begin{array}{c}\text { Độ nhạy } \\
(\mathbf{\%})\end{array}$ & $\begin{array}{c}\text { Độ đặc hiệu } \\
\mathbf{( \% )}\end{array}$ & PPV (\%) & NPV (\%) \\
\hline $\mathrm{PaCO}_{2}$ & 0,8364 & 88 & 81,8 & 86,2 & 69,2 & 92,6 \\
\hline $\mathrm{PIP}$ & 0,8871 & 17 & 63,6 & 93,1 & 77,8 & 87,1 \\
\hline Leak & 0,7884 & 29 & 63,64 & 79,31 & 53,8 & 85,2 \\
\hline
\end{tabular}

Nhận xét: $\mathrm{PaCO}_{2}$ với điếm cắt $\geq 88 \mathrm{mmHg}$, PIP với điếm cắt $\geq 17 \mathrm{cmH}_{2} \mathrm{O}$, Leak với điếm cắt $\geq 29$ lít/phút cho độ nhạy, độ đặc hiệu, giá trị dự báo dương tính và giá trị dự báo âm tính cao. 

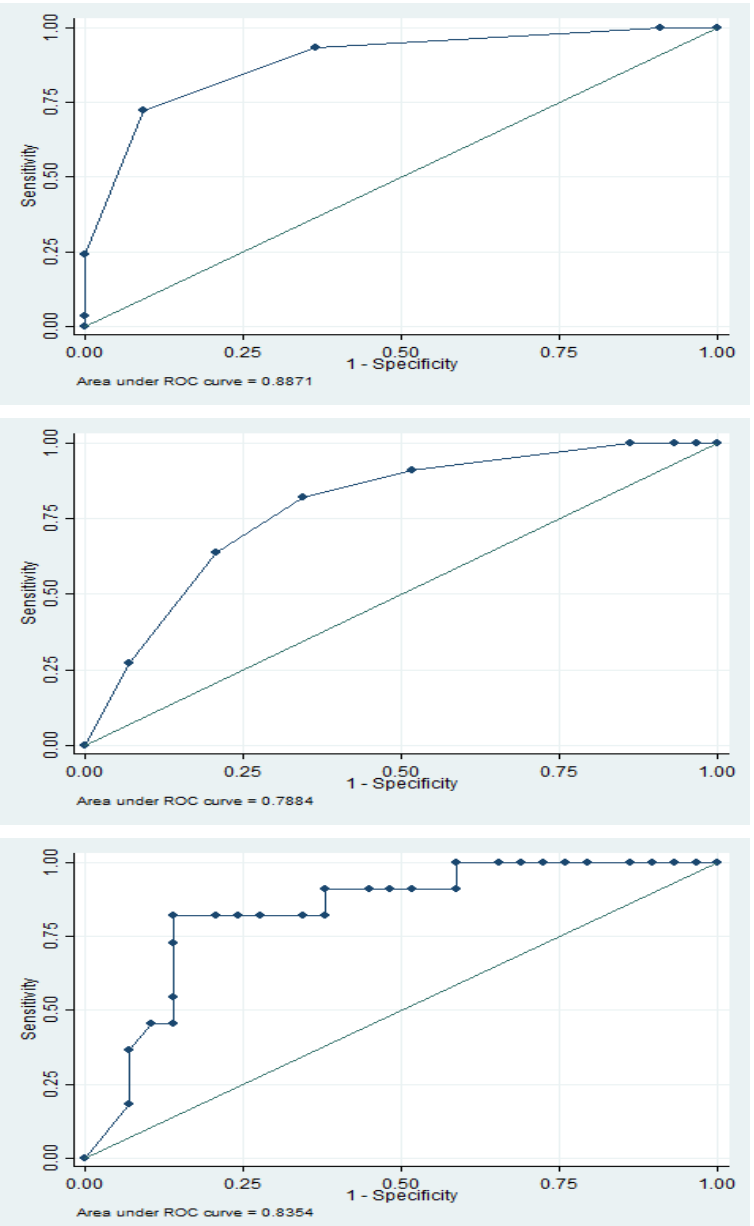

Biểu đồ 2. Đường cong ROC cho các giá trị của PIP (trái), Leak (phải) và $\mathrm{PaCO}_{2}$ (dưới) trong tiên Iượng can thiệp thành công $(n=40)$

Đường cong ROC cho các giá trị của PIP trong tiên lượng can thiệp thành công cho diện tích dưới đường cong (AUC) giá trị cao là 0,8871. Đường cong ROC cho các giá trị của Leak trong tiên lượng can thiệp thành công cho diện tích dưới đường cong (AUC) giá trị cao là 0,7884. Đường cong $\mathrm{ROC}$ cho các giá trị của $\mathrm{PaCO}_{2}$ trong tiên lượng can thiệp thành công cho diện tích dưới đường cong (AUC) giá trị cao là 0,8364.

\section{BÀN LUÂN}

Nghiên cứu của chúng tôi trên 40 bênh nhân độ tuổi trung bình là $70,3 \pm 9,87$ tuổi; đa số đối tượng nằm trong độ tuổi $60-80$. Nam giới chiếm phần lớn bệnh nhân $(92,5 \%)$, điều này có thể giải thích do tiền sử liên quan đến việc thói quen sử dụng thuốc lào, thuốc lá của nam giới nhiều hơn ở nữ giới

Trong 40 bệnh nhân nghiên cứu cho kết quả có 29 bệnh nhân $(72,5 \%)$ thành công. Tỉ lệ can thiệp thành công trong nghiên cứu của chúng tôi tương tự như kết quả của Confalonieri $(77,2 \%)[7]$ và nghiên cứu của Fatma $(76,4 \%)$ [8]. Trong nghiên cứu này, tình trạng khí máu và cơ học phổi các chỉ số của bệnh nhân lúc nhập viện không có sự khác biệt giữa 2 nhóm thành công và thất bại. Thời gian điều trị 3,4 \pm 4,2 ngày, với nhóm can thiệp thành công trung bình là 2,7 $\pm 3,6$ ngày, nhóm can thiệp thất bại là 5,4 $\pm 4,9$ ngày; thời gian thở máy trung bình $1,3 \pm$ 0,7 ngày.Thời gian điều trị thở máy giữa 2 nhóm không có sự khác biệt[9], tuy nhiên, trong nghiên cứu của chúng tôi, thời gian điều trị ở nhóm thành công ngắn hơn so với số ngày điều trị ở nhóm thất bại, trong khi ở nghiên cứu trước chưa có sự khác biệt này[9]. Phương pháp AVAPS giúp tăng hiệu quả điều trị, giảm thời gian và chi phí cho bệnh nhân [5], [6].

Biết được khả năng thất bại của thông khí nhân tạo không xâm nhập ở bệnh nhân đợt cấp của bệnh phổi tắc nghẽn mạn tính có thể chỉ ra sự lựa chọn tốt nhất giữa thông khí nhân tạo không xâm nhập và đặt nội khí quản được đặt trước đó. Trong nghiên cứu của chúng tôi, sử dụng $\mathrm{PaCO}_{2}$ với điểm cắt $\geq 88 \mathrm{mmHg}$, PIP với điểm cắt $\geq 17 \mathrm{cmH}_{2} \mathrm{O}$, Leak với điểm cắt $\geq 29$ lít/phút cho độ nhạy, độ đặc hiệu, giá trị dự báodương tính và giá trị dự báo âm tính cao, có giá trị trong việc tiên đoán khả năng thành công của phương pháp. Nghiên cứu thực hiện tại Thổ Nhĩ Kì, sử dụng mô hình hồi quy Cox cho kết quả sự thay đổi trong $\mathrm{PaCO}_{2}$ có tương quan với thất bại điều trị ( $R R=1,278,95 \% \mathrm{CI}$ : 1,067-3,235, $\mathrm{p}=0,02)$, từ đó $\mathrm{PaCO}_{2}$ mang giá trị dự báo cho bệnh nhân [8]. Nghiên cứu của Confalonieri tại Ý trền 1.033 bệnh nhân nhằm tìm hiểu yếu tố nguy cơ thất bạu cho thấy: bệnh nhân có Điểm hôn mê Glasgow < 11, điểm APACHE II $\geq 29$,

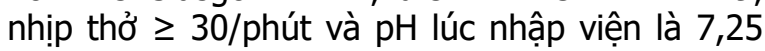
có nguy cơ thất bại được dự đoán là $70 \%$. Độ $\mathrm{pH}<7,25$ sau 2 giờ nhập viện làm tăng đáng kể nguy cơ (90\%)[7].

Nghiên cứu của chúng tôi còn có những hạn chế như bệnh nhân có pH trung bình lớn hởn 7,25, trong khi các nghiên cứu khác có giá trị pH trung bình thấp hơn [1], [7]. Cõ mẫu của chúng tôi nhỏ, cần có những nghiên bổ sung để đưa đưa ra những kết luận có thể đại diện tốt cho quần thể nghiên cứu.

\section{KẾT LUẬN}

Các yếu chính như $\mathrm{PaCO} 2$ (điểm cắt $\geq 88$ $\mathrm{mmHg}$ ), PIP (điểm cắt $\geq 17 \mathrm{cmH}_{2} \mathrm{O}$ ), leak (điểm cắt $\geq 29$ lít/phút) là những yếu tố tiên lượng 
thành công khi bắt đầu thở không xâm nhập bằng phương thức AVAPS.

\section{TÀI LIẸU THAM KHẢO}

1. Gold Reports (2019). Global Initiative for Chronic Obstructive Lung Disease - GOLD. <http://goldcopd.org/gold-reports/>, accessed: 28/09/2020.

2. Schmidt M., Demoule A., Deslandes-Boutmy E. và cộng sự. (2014). Intensive care unit admission in chronic obstructive pulmonary disease: patient information and the physician's decision-making process. Crit Care, 18(3), R115.

3. Ai-Ping C., Lee K.-H., và Lim T.-K. (2005). Inhospital and 5-year mortality of patients treated in the ICU for acute exacerbation of COPD: a retrospective study. Chest, 128(2), 518-524.

4. Breen D., Churches T., Hawker F. và cộng sự. (2002). Acute respiratory failure secondary to chronic obstructive pulmonary disease treated in the intensive care unit: a long term follow up study. Thorax, 57(1), 29-33.

5. Storre J.H., Seuthe B., Fiechter R. và cộng sự. (2006). Average volume-assured pressure support in obesity hypoventilation: A randomized crossover trial. Chest, 130(3), 815-821.

6. Murphy $P_{.}$, Davidson $C_{\text {., }}$ Hind $M$. và cộng sự. (2012). Volume targeted versus pressure support non-invasive ventilation in patients with super obesity and chronic respiratory failure: $A$ randomised controlled trial. Thorax, 67, 727-34.

7. Confalonieri M., Garuti G., Cattaruzza M.S. và cộng sự. (2005). A chart of failure risk for noninvasive ventilation in patients with COPD exacerbation. Eur Respir J, 25(2), 348-355.

8. Ciftci F. (2017). Evaluation of the feasibility of average volume-assured pressure support ventilation in the treatment of acute hypercapnic respiratory failure associated with chronic obstructive pulmonary disease: A pilot study. Journal of Critical Care, 40.

9. Briones Claudett K.H., Briones Claudett M., Chung Sang Wong M. và công sứ. (2013). Noninvasive mechanical ventilation with average volume assured pressure support (AVAPS) in patients with chronic obstructive pulmonary disease and hypercapnic encephalopathy. BMC Pulm Med, 13, 12.

\section{NHU CẦU VÀ GIẢI PHÁP PHÁT TRIỂN CÔNG ĐOÀN TẠI CƠ SỞ Y TẾ NGOÀI CÔNG LẬP}

\section{Nguyễn Đức Hữu ${ }^{3}$}

TÓM TẮT

Mục tiêu: Mô tả thực trạng và nhu câu của người lao đông tai các cơ sở y tế ngoài công lập và giải pháp. Phương pháp: Nghiên cứu mô tả cắt ngang, sử dụng kết hợp phương pháp nghiên cứu định tính và định lượng; nghiên cứu bàn giấy kết hợp với nghiên cứu thực đia 543 người lao động ở cơ sở y tế ngoài công lập đã thành lập và chưa thành lập công đoàn tại Hà Nội, Hồ Chí Minh và Đà Nẵng. Kểt quả: năm 2019 các cơ sở Y tế ngoài công lập có xu hướng gia tăng 14,5\% so với năm 2018, nhưng chỉ có 0,65\% tổ chức công đoàn được thành lập. Số liệu thống kê cơ sở y tế ngoài công lập chưa thống nhất giữa Sở $Y$ tế và Liên đoàn Lao động. Người lao động tham gia tổ chức công đoàn được hưởng lợi nhiều hơn lao đông ở các tổ chức chưa tham gia công đoàn về bảo hiểm xã hội, bảo hiểm y tế, bảo hiểm tai nạn và Phụ cấp đô̂c hại, phụ cấp trách nhiệm. Đặc biệt cơ sở đã thành lập công đoàn thì trang thiết bị bảo hộ

${ }^{1}$ Công đoàn Y tế Việt Nam

${ }^{2}$ Nghiên cứu viên Viện Chiến lược và Chính sách Y tế

${ }^{3}$ Trường Đại học Công đoàn

"Viện Công nhân và Công đoàn

Chịu trách nhiệm chính: Phạm Thanh Bình

Email: thanhbinhpham123456@gmail.com

Ngày nhận bài: 3.3.2021

Ngày phản biện khoa học: 26.4.2021

Ngày duyệt bài: 7.5.2021
Phạm Thanh Bình' ${ }^{1}$ Hoàng Thị Mỹ Hạnh², Nguyễn Thanh Tùng ${ }^{4}$, Trần Thị Thu Hiền ${ }^{1}$ đây đủ có tỷ lệ $65,8 \%$ cao hơn so với tổ chức y tê ngoài công lập chưa thành lập công đoàn chỉ đạt $46,7 \%$. Các đối tượng được phỏng vấn có $74.9 \%$ mong muốn các tổ chức đại diện người lao động bảo vệ tốt hơn cho người lao động; 71,9\% cho biết họ không muốn có tổ chức đại diện người lao động không thuộc hệ thống công đoàn trong các cơ sở y tế ngoài công lập; còn lại 22,7\% chưa biết lập trường, quan điểm của mình. Về phương pháp tâp hợp đoàn viên thì trên $70 \%$ người được hỏi cho rằng phải kết hợp hai phương pháp từ dưới lên và từ trên xuống. Kểt luận: đổi mới phương thức tập hợp người lao đông ở cơ sở y tế ngoài công lập là yêu cầu cấp bách đối với các cấp công đoàn.

Tư khóa: Công đoàn cơ sở (CĐCS), Cơ sở y tế ngoài công lập (CSYTNCL), tập hợp đoàn viên; Đổi mới phương thức, CPTPP; EVFTA; Công đoàn ghép; Kết hợp phương thức cũ và mới.

\section{SUMMARY \\ NEEDS AND SOLUTIONS FOR TRADE UNION DEVELOPMENT IN NON-PUBLIC HEALTHCARE INSTITUTIONS}

Objective: The paper describes the current situation and needs of workers in non-public healthcare facilities as well as solutions. Method: This study employs a cross-sectoral descriptive design with a combination of quantitative and qualitative research; Desk research combined with field research of 543 workers in non-public healthcare with and 